Kalcounis, M.C. and R.M. Brigham. 1998. Secondary use of aspen cavities

by tree roosting big brown bats. Journal of Wildlife Management 62(2): 603-611.

Made available courtesy of the Wildlife Society: http://joomla.wildlife.org/

\title{
SECONDARY USE OF ASPEN CAVITIES BY TREE-ROOSTING BIG BROWN BATS
}

MATINA C. KALCOUNIS, ${ }^{1,2}$ Department of Biology, University of Regina, Regina, SK S4S OA2, Canada

R. MARK BRIGHAM, Department of Biology, University of Regina, Regina, SK S4S OA2, Canada

Abstract: To further explore natural roost-site selection by temperate bats, we examined the use of tree roost sites by big brown bats (Eptesicus fuscus) in the West Block of Cypress Hills Provincial Park, Saskatchewan an area where the number of human structures is limited. In this area, we found big brown bats roosted exclusively in cavities of trembling aspen trees (Populus tremuloides), despite the availability of cavities in snags of conifer trees. Most cavities had been excavated and previously used by yellow-bellied sapsuckers (Sphyrapicus varius). The use of aspens by sapsuckers relates to the relatively soft wood and susceptibility to heart rot of these trees, which provide ideal conditions for nesting: decayed heartwood with a firm sapwood shell. Orientation of cavity entrances was close to due south. The width of bats and the width of cavity entrances differed, suggesting that bats are not using roosts for protection from predators or exclusion of competitors Bats showed fidelity to a particular group of roost trees because, despite roost switching, bats reunited in subsequent roost sites. During the day, temperatures in aspen cavities were approximately $5^{\circ} \mathrm{C}$ cooler than in cavities of conifer snags. Microclimate differences, including temperature, may be why aspen cavities are selected over available cavities in conifer snags. All of the randomly selected cavities in aspen that we searched showed evidence of use by bats, which suggests roost sites for big brown bats in southwestern Saskatchewan may be a limiting resource.

JOURNAL OF WILDLIFE MANAGEMENT 62(2):603-611

Key words: bats, Eptesicus fuscus, habitat complexity, maternity colony, roost, switching, temperature, treecavity, trembling aspen.

In comparison to use of nest sites by birds, relatively little is known about use of roost sites by bats, especially use of natural roosts such as tree cavities. The majority of ecological and behavioral research on temperate insectivorous bats (Chiroptera: Vespertilionidae) is from species roosting in human structures, because it is easier to find and access bats roosting in a hu-

${ }^{1}$ Present address: Ecology and Evolution Group, Department of Zoology, University of Western Ontario, London, ON N6A 5B7, Canada.

2 E-mail: matina@julian.uwo.ca man structure than in a natural site such as a tree cavity. As a result, factors that influence selection of roost sites by bats under natural conditions where human structures are not abundant are poorly understood (for review see Brigham and Barclay 1996).

Selection of specific roost sites by breeding female bats has consequences to survival and reproductive success (Entwistle et al. 1997), and there is mounting evidence that bats choose roost sites for reasons of microclimate, protection from predators, avoidance of parasites, and 
Kalcounis, M.C. and R.M. Brigham. 1998. Secondary use of aspen cavities

by tree roosting big brown bats. Journal of Wildlife Management 62(2): 603-611. Made available courtesy of the Wildlife Society: http://joomla.wildlife.org/

social interaction (this study; also see reviews in Lewis 1995, 1996). Roost type (building, tree cavity, rock crevice, cave) may be unimportant to bats, provided roost type satisfies other requirements such as characteristics of the roost or the habitat surrounding the roost. Physical characteristics of a roost can influence the protection afforded by the roost and the microclimate within the roost, whereas amount of habitat surrounding the roost can influence flight performance capabilities of both juvenile and adult females and can influence predation risk to individuals in the roost.

Nonetheless, the influence of roost microclimate on use of roost sites is not clear. For example, the leaf-nosed bat (Hipposideros speoris) exhibits high fidelity to dark roost sites within caves (Usman 1988), whereas the Indiana bat (Myotis sodalis) uses tree-roost sites in unshaded locations (Kurta et al. 1993a,b). Similarity in internal temperatures between different roost types suggests that selection of roost sites may involve locating a specific range of thermal conditions. For example, in South Africa, bats from the family Rhinolophidae select roosts in hollow baobab trees (Adansonia digitate), Vespertilionidae select roosts in hollow mopane trees $(\mathrm{Col}$ ophospermum mopane), and Molossidae select roosts in building attics because all roosts offer similar temperature regimes (Fenton and Rautenbach 1986). Further, the orange horseshoe bat (Rhinonycteris aurantius) in India occupies a narrow range of available humidity in its cave roost sites (Churchill 1991).

The ontogeny of juvenile flight (Adams 1997) and the decreased maneuverability of pregnant bats (Norberg and Rayner 1987) may make less complex habitat around entrances to roost trees a preferred characteristic. Juvenile bats in tree hollows, in contrast to bats roosting in buildings, are generally unable to perform practice flights before venturing outside for the first time. When juvenile little brown bats (Myotis lucifugus) take their first flights, they remain close to the roost, avoid acoustically complex habitat, and do not pursue insects (Buchler 1980). Increases in body mass also affect habitat use by little brown bats whereby heavier bats forage in less complex habitats (Kalcounis and Brigham 1995). Pregnant female bats may therefore select roost sites where the number of objects to detect and avoid in front of the cavity entrance is low.

Not only is habitat complexity relevant in terms of flight, but predation risk may differ between simple and complex habitats. When individuals emerge from a maternity colony, many individuals may exit in a relatively short period, which makes the event conspicuous (Speakman et al. 1992). Emergence is also highly correlated with sunset and is therefore predictable in time (Kalcounis and Brigham 1994). Thus, if bats perceive a predation risk, they may select roosts surrounded by complex habitat to conceal predictable and conspicuous emergence events.

The purpose of this paper is to describe the suite of physical characteristics, including roost microclimate, that define big brown bat roost trees in Cypress Hills Provincial Park, Saskatchewan, where this species exclusively roosted in the cavities of trembling aspen (Kalcounis 1995). We also test the hypotheses that (1) to avoid predators and competitors, big brown bats choose roost sites with cavity entrances not much larger than themselves; (2) the complexity of the habitat directly in front of the roost-cavity opening is lower than that in other directions; and (3) the thermal microclimate of cavities used by big brown bats (in aspen) will differ from cavities not used by bats (in conifer snags).

\section{STUDY AREA}

This study was conducted during the summers of 1993 and 1994, within the West Block of Cypress Hills Provincial Park $\left(49^{\circ} 34^{\prime} \mathrm{N}\right.$, $109^{\circ} 53^{\prime} \mathrm{W}$ ), approximately $60 \mathrm{~km}$ southwest of Maple Creek, Saskatchewan. The Cypress Hills run about $50 \mathrm{~km}$ in an east-west direction and form the highest elevated plateau in the Canadian prairies (Sauchyn 1993). Lodgepole pine (Pinus contorta) forest occupies dry sites above 1,300 $\mathrm{m}$, and white spruce (Picea glauca) forest occurs in cool, moist areas near wetlands and on north-facing slopes. The understory of spruce forest is relatively diverse and includes several plant species with distributions disjunct from mountain populations. Trembling aspen is found growing with white spruce near streams on south-facing slopes.

\section{METHODS \\ Data Collection}

Locating Roost Trees.-We located roost trees by tracking radiocollared bats or by searching randomly selected cavities for the evidence of use by bats. For the purpose of radiotelemetry, we initially used mist nets to capture bats. Upon capture, we affixed 0.8 -g trans- 
Kalcounis, M.C. and R.M. Brigham. 1998. Secondary use of aspen cavities by tree roosting big brown bats. Journal of Wildlife Management 62(2): 603-611. Made available courtesy of the Wildlife Society: http://joomla.wildlife.org/

mitters (BD-2T, Holohil Systems, Woodlawn, Ontario, Canada) via Skinbond cement. Individuals carrying radiotransmitters were tracked to their roosts the morning following capture via Merlin 12 (Custom Electronics, Urbana, Illinois, USA) portable telemetry receivers and hand-held Yagi antennae. When we located a roost tree, it was observed at dusk to ensure it was used by bats and to determine colony size.

We defined a random site as an aspen tree with a cavity opening of $>4.0 \mathrm{~cm}$ because all big brown bats roosted in aspen trees and required an opening greater than their body width to enter the cavity. We selected random sites via randomly generated distance and direction tables. To access cavities (to check random cavities and take measurements on roost cavities), we climbed trees with tie-on treeclimbing steps and a standard climbing harness and ropes. We checked randomly selected cavities for evidence of use by bats by scraping the bottom and sides of the cavity with a long-handled spoon to retrieve bat droppings.

Characteristics of Roost Sites.-Characteristics recorded for each roost tree included tree condition (live or dead), height and diameter at breast height $(\mathrm{dbh})$, percent cover by neighboring trees (number of branches from neighboring trees that fell within $1 \mathrm{~m}$ of the tree), and number of cavity openings. We also recorded the presence or absence of fruiting bodies of heart-rot fungus (hoof-shaped conks) on tree trunks because fruiting bodies are external indicators of false tinder rot (Fomes igniarius; Peterson and Peterson 1992).

Characteristics recorded for each cavity included height, entrance orientation, width (dimension perpendicular to trunk axis) and length (dimension parallel to trunk axis) of the cavity entrance, light intensity as a proportion of ambient light intensity (Model 840006 light meter; Sper Scientific, Tempe, Arizona, USA), percent relative humidity as a proportion of ambient percent relative humidity (Model 880 humidity meter; General Eastern, Woburn, Maryland, USA) at solar noon, and percent of cavity opening covered by its own tree foliage and by neighbor tree foliage (determined by estimating how many branches, foliage, or both fell within $1 \mathrm{~m}^{2}$ of the entrance). We took all measures of light intensity and percent relative humidity between 1 and 14 August 1994 to minimize variation due to canopy development.

To generate predictions regarding the width

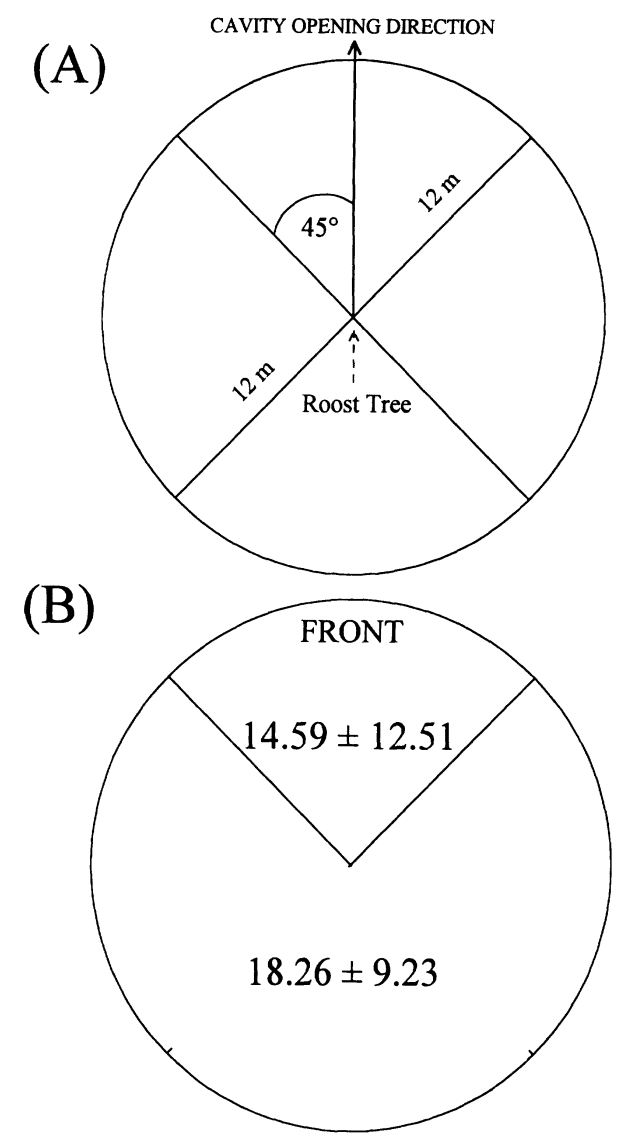

Fig. 1. (A) 12-m-radius circular plot divided into quadrants for measuring and calculating Habitat Complexity Indices. (B) Habitat Use Indices (mean $\pm 1 S D$ ) for quadrant in front of the roost opening and the 3 other quadrants.

of the cavity entrance, we measured width of bats from elbow-to-elbow because this distance is the widest part of a bat, and thus the dimension most likely to constrain selection of tree cavities. Using calipers, we made 3 measurements of width for each individual. To maximize sample size, we measured individuals from a colony of over 100 big brown bats roosting in the attic of Elm Street School in nearby Medicine Hat, Alberta $\left(50^{\circ} 02^{\prime} \mathrm{N}, 111^{\circ} 40^{\prime} \mathrm{W}\right)$.

Habitat Complexity.-To quantify habitat complexity around roost trees, we determined distance (from the roost tree) and estimated height (as a percent of canopy height) for all trees within a 12-m-radius circular plot centered at the roost tree (Fig. 1A). We established 
Kalcounis, M.C. and R.M. Brigham. 1998. Secondary use of aspen cavities

by tree roosting big brown bats. Journal of Wildlife Management 62(2): 603-611. Made available courtesy of the Wildlife Society: http://joomla.wildlife.org/

the position of every tree within the circular plot by determining the direction and distance of each tree from the roost tree. A Habitat Complexity Index (HCI) was calculated using the following equation:

$$
\mathrm{HCI}=\Sigma[\log (h) \cdot 1 / \log (d)],
$$

where $h$ is the height of the tree (expressed as percent of canopy height), and $d$ is the distance (m) of the tree from the roost tree. This index reflects the average complexity of the habitat around the roost tree such that a higher index indicates relatively more close, tall trees.

We divided the circular plot into quadrants such that 1 quadrant was bisected by the entrance orientation (Fig. 1A). We calculated an $\mathrm{HCI}$ for the cavity-opening quadrant (hereafter, front habitat) and for the remaining 3 quadrants (hereafter, back habitat). We scaled the back HCI for the differences in area between the front and back habitat by dividing the HCI of back habitat by 3 . The HCI index may confound the effects of the variables in the equation and thereby increase the likelihood of Type II errors. Therefore, we also analyzed each characteristic separately (i.e., number of trees, height and distance from the roost tree).

Thermal Microclimate.-We used temperature-sensitive radiotransmitters $(\mathrm{PD}-2 \mathrm{~T}$ and BD-2T, Holohil Systems, Woodlawn, Ontario, Canada) to compare ambient temperature with temperature profiles of the cavity types used by bats (aspen) and the available cavities not used by bats (snags of conifers). We defined conifer snags as dead white spruce or lodgepole pine trees with cavities and tree tops broken off. We placed transmitters in unoccupied cavities by climbing the trees and suspending the transmitter in the cavity via monofilament fishing line. We randomly selected 2 cavities from the group of roost trees, 2 cavities in aspen trees, and 2 cavities from conifer snags. The transmitter measuring ambient temperature was suspended, in midair, between 2 trees near the receiver (see below).

To measure temperatures, we used an automated telemetry receiver (Lotek SRX 400 telemetry receiver with Event Log Version 2.62 W18 logging software; Lotek Engineering, Aurora, Ontario, Canada). We programmed the receiver to record the temperature of each transmitter hourly from 13-26 July 1994. Complete 24-hr profiles were obtained for 6 days, while partial profiles (>12 hr/24-hr period) were obtained for 4 days.

\section{Statistical Analysis}

All data on tree and cavity characteristics are presented as mean \pm 1 standard deviation. Comparisons of body and cavity width and HCI indices between front and back habitat were made with parametric $t$-tests. We used an analysis of variance (ANOVA) to test for HCI equation variables individually (number, height, distance of trees). Entrance orientation data were corrected to true north and analyzed with a Rayleigh test (Zar 1984) to determine whether entrance orientations were randomly distributed around a circle. To compare temperature profiles between aspen and conifer snag cavities, we divided each sampling day into 4 time blocks reflecting night (0000-0559), morning (0600-1159), afternoon (1200-1759), and evening (1800-2359). Temperatures recorded in each time period were pooled over the $10 \mathrm{sam}$ pling days. We performed ANOVA and, where appropriate, post hoc comparisons of means (Tukey HSD) on the temperature data. Temperature data are reported as mean \pm 1 standard error. We used $\alpha=0.05$ as a rejection criterion for all statistical tests.

\section{RESULTS}

We marked 11 adult female big brown bats with radiotags, and we found 27 roost trees (16 from radiotracking, 11 from random cavity searches). Of the 16 roost trees found from radiotracking, 10 were found in 1993 and 6 were found in 1994. We watched the emergence of colonies from roosts on 19 nights. Colony size ranged from 2 to 43 individuals with a mean ( \pm SD) of $20.7 \pm 13.1$ individuals. The colonies were maternity colonies composed of juveniles and pregnant, lactating, and postlactating adult females. Individuals did not remain in a single roost tree for the entire season, and at least 4 radiocollared bats stayed in roost trees for no more than 1 night. Two of the 10 roosts found in 1993 were used again by big brown bats in 1994. At least 1 radiocollared bat returned to a previously used roost site within 1 year. On 4 occasions, radiocollared bats (which were known to have roosted together) reunited in subsequent roost sites, suggesting that bats show fidelity to a particular group of roost trees. In 2 roosts with $>1$ cavity opening, red squirrels (Tamiasciurus hudsonicus) were seen entering 
Kalcounis, M.C. and R.M. Brigham. 1998. Secondary use of aspen cavities by tree roosting big brown bats. Journal of Wildlife Management 62(2): 603-611. Made available courtesy of the Wildlife Society: http://joomla.wildlife.org/

Table 1. Characteristics of roost trees and cavities used by big brown bats in Cypress Hills Provincial Park during the summers of 1993 and 1994.

\begin{tabular}{llrrc}
\hline \multicolumn{1}{c}{ Characteristic } & $n$ & $\bar{x}$ & SD & Range \\
\hline Tree & & & & \\
Height (m) & 27 & 25.6 & 7.7 & $13.6-51.8$ \\
Dbh (cm) & 27 & 35.8 & 7.2 & $22.8-57.1$ \\
Percent cover & 27 & 33.5 & 23.4 & $0-75.0$ \\
$\quad$ Number of entrances & 27 & 2.0 & 1.3 & $1.0-5.0$ \\
Cavity & & & & \\
Height (m) & 26 & 8.4 & 2.9 & $4.3-14.6$ \\
Relative humidity & 24 & 1.3 & 0.3 & $0.6-1.9$ \\
Light intensity & 24 & 0.8 & 0.3 & $0.2-1.0$ \\
Percent cover by self & 26 & 11.4 & 18.9 & $0-50.0$ \\
Percent cover by neighbours & 26 & 10.0 & 23.5 & $0-75.0$ \\
Length (mm) & 21 & 255.4 & 606.5 & $40.0-2,700.0$ \\
Width (mm) & 21 & 45.7 & 11.6 & $25.8-70.0$ \\
\hline
\end{tabular}

the cavity from 1 opening while bats emerged from another.

\section{Characteristics of Roost Sites}

All roost trees were trembling aspen: 24 were live trees, and 3 were dead trees. All live roost trees had symptoms of fungal heart rot in the form of conks. Most (at least 73\%) cavities were originally excavated by sapsuckers or other woodpeckers. On several occasions, yellow-bellied sapsuckers were seen excavating nest cavities in aspen trees that had entrance dimensions consistent with those of the roost cavities. Some cavities (at least $23 \%$ ) originated as branch scars or splits in the trunks of trees.

Tree and cavity characteristics of roosts are given in Table 1 . We were unable to reach the cavity of 1 live roost tree or 2 of the dead roost trees, and therefore could not measure their cavity characteristics. The mean orientation of cavities $\left(169.39 \pm 16.23^{\circ}\right)$ was close to due south, and cavity orientations were not uniformly distributed $\left(Z_{26}=2.97, P<0.001\right)$. The mean body width of big brown bats (39.82 \pm $0.66 \mathrm{~mm}, n=21$ ) was smaller than the width of cavity entrances $\left(45.37 \pm 2.09 \mathrm{~mm} ; F_{1,45}=\right.$ 5.32, $P<0.03$ ).

\section{Habitat Complexity}

There was no difference between the HCI in the front and back of roost trees $\left(F_{1,52}=1.51\right.$, $P>0.05$; Fig. 1B). Similarly, there was no difference between the mean number of trees, the height, or the distance from the roost tree in the area in front and back of roost trees $(P>$ 0.05; Table 2).

\section{Thermal Microclimate}

Over the 10-day sampling period, mean temperatures differed during the time blocks of night $\left(F_{2,189}=21.22, P<0.001\right)$, morning $\left(F_{2,189}=33.18, P<0.001\right)$, afternoon $\left(F_{2,230}=\right.$ $4.80, P<0.01)$, and evening $\left(F_{2,192}=10.26, P\right.$ $<0.001$; Fig. 2). For the post hoc mean comparisons, an experimentwise error rate $(\alpha)$ of 0.05 was used, and the critical $q$-value for all comparisons was 3.314 (Zar 1984). Aspen cavities were warmer than ambient temperature but cooler than conifer snag cavities at night $\left(q_{189,3}\right.$ $=5.33, P<0.001$ ). In the morning, aspen cavities were cooler than ambient temperature $\left(q_{189,3}=9.30, P<0.001\right)$ and conifer snag cavities $\left(q_{189,3}=9.51, P<0.001\right)$, which did not differ from each another $\left(q_{189,3}=0.18, P>\right.$

Table 2. Habitat characteristics in front and back of roost trees used by big brown bats in Cypress Hills Provincial Park during the summers of 1993 and 1994.

\begin{tabular}{|c|c|c|c|c|c|c|c|}
\hline \multirow[b]{2}{*}{ Characteristic } & \multicolumn{2}{|c|}{ Front } & \multicolumn{2}{|c|}{ Back } & \multirow[b]{2}{*}{$\mathrm{df}$} & \multirow[b]{2}{*}{$F$} & \multirow[b]{2}{*}{$P$} \\
\hline & $\bar{x}$ & SD & $\bar{x}$ & SD & & & \\
\hline Number of trees & 7.74 & 5.52 & 7.09 & 3.77 & 1,52 & 0.20 & 0.62 \\
\hline Height of trees (\%) & 88.76 & 14.31 & 87.33 & 9.60 & 1,51 & 0.18 & 0.67 \\
\hline Distance of trees from roost $(\mathrm{m})$ & 8.98 & 1.81 & 8.37 & 1.02 & 1,52 & 2.35 & 0.13 \\
\hline
\end{tabular}


Kalcounis, M.C. and R.M. Brigham. 1998. Secondary use of aspen cavities by tree roosting big brown bats. Journal of Wildlife Management 62(2): 603-611. Made available courtesy of the Wildlife Society: http://joomla.wildlife.org/

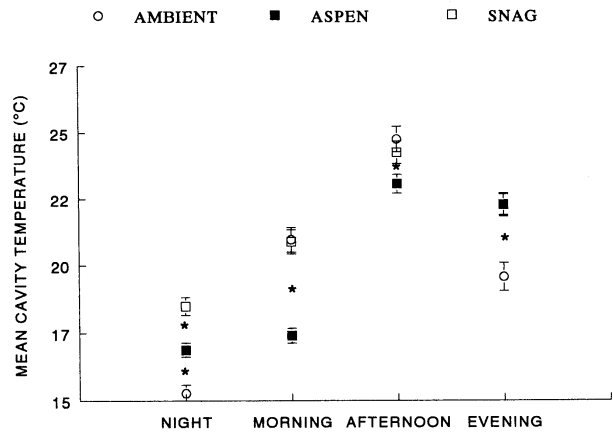

Fig. 2. Mean ( $\pm \mathrm{SE}$ ) temperatures over 10 days of sampling in the 4 time blocks reflecting night (0000-0559), morning (0600-1159), afternoon (1200-1759), and evening (18002359). Means separated by an asterisk are significantly different $(P<0.05$; Tukey's test $)$.

0.05). In the afternoon, aspen cavities were cooler than ambient temperature $\left(q_{230,3}=4.07\right.$, $P<0.05)$ but did not differ from conifer snag cavities $\left(q_{230,3}=1.06, P>0.05\right)$. Both aspen $\left(q_{192,3}=6.03, P<0.001\right)$ and conifer snag $\left(q_{189,3}=5.25, P<0.001\right)$ cavities were warmer than ambient temperature in the evening. The difference between aspen cavities and conifer snag cavities was greatest in the morning.

\section{DISCUSSION}

\section{Characteristics of Roost Sites}

Although most commonly found roosting in buildings (Brigham and Fenton 1986), big brown bats have been found roosting in natural hollows of beech (Fagus grandifolia; Kurta 1980), ponderosa pine (Pinus ponderosa; Brigham 1991), and western redcedar (Thuja plicata; Vonhof and Barclay 1996), as well as rock crevices (Brigham 1991). In the Cypress Hills, big brown bats are secondary cavity roosters that use both live and dead aspen trees, despite the availability of cavities in conifer snags. Most of the aspen cavities had been excavated and used by sapsuckers as nest sites. As secondary cavity users, bats choose cavities from among those already excavated and are therefore constrained by the preferences of the primary cavity excavators for nesting sites and by the decay characteristics of the tree and cavity. The use of aspens by primary cavity excavators such as sapsuckers is related to the aspen's relatively soft wood and susceptibility to heart rot. False tinder rot is a major cause of decay in aspens (Basham 1958, Peterson and Peterson 1992) that in- duces extensive decomposition of heartwood while sparing sapwood, which remains as a tough, living outer shell (Kilham 1971). In contrast, white spruce and lodgepole pine do not have the same decay characteristics as aspen (Peterson and Peterson 1992). In conifers, heartwood and sapwood both decay more rapidly, which precludes the formation of a solid outer shell of sapwood (McClelland et al. 1979). In the Cypress Hills, suitability and use of aspens for nesting and subsequent roosting sites seem determined both by the availability of aspen as the only dominant hardwood and by its decay characteristics.

Cavity orientation can enhance microclimate effects, and many birds derive thermoregulatory benefits from specific orientations of nest sites by avoiding direct wind exposure (Austin 1976, Williams 1993, Haggerty 1995) and sun (Inouye et al. 1981, Korol and Hutto 1984), or facilitating direct exposure to sun (Inouye 1976, Smith et al. 1987). Sapsuckers and other woodpeckers tend to excavate nests on the south-facing side of trees (Reller 1972, Crockett and Hadow 1975 , Inouye 1976), which is probably an adaptive response by sapsuckers to the prevailing east-west wind and relatively cool spring temperatures in the Cypress Hills. The predominant southerly orientation of cavity entrances suggests that cavity orientation confers some benefit to the sapsuckers that excavate the cavities and to the big brown bats that subsequently roost in the cavities.

The width of bats was significantly smaller than the width of roost entrances. Throughout their range, sapsuckers excavate nest cavities with circular entrances having consistent dimensions. In British Columbia (Erskine and McClaren 1972) and 2 sites in Colorado (Inouye 1976, Winternitz and Cahn 1983), the mean diameters of sapsucker nest entrances were between 3.5 and $4.1 \mathrm{~cm}$. In our study, the mean diameter of entrances was $4.5 \mathrm{~cm}$. The discrepancy between the mean diameter of entrances in this study and previous investigations can be attributed to decay of sapwood around the entrance hole in the older sapsucker cavities that were used secondarily by bats. The difference between the width of bats and the width of roost entrances, along with the observation of red squirrels entering cavities, suggests bats do not select cavities that preclude entrance by predators, competitors, or both. 
Kalcounis, M.C. and R.M. Brigham. 1998. Secondary use of aspen cavities

by tree roosting big brown bats. Journal of Wildlife Management 62(2): 603-611. Made available courtesy of the Wildlife Society: http://joomla.wildlife.org/

\section{Habitat Complexity}

Relative to other temperate Vespertilionidae, big brown bats are large and have a low echolocation call frequency (Norberg and Rayner 1987). Because of these characteristics, big brown bats should be restricted to flying in more open habitat (see Norberg and Rayner 1987). In our study, however, the complexity of habitat surrounding the roost site was not a factor influencing use of a roost site. One problem associated with field studies that attempt to correlate habitat selection to habitat complexity in bats is the difficulty in determining how complex a habitat must be before a species is no longer maneuverable enough to fly there. Although all roost trees in our study were in the middle of mixed aspen-spruce forests, adult and juvenile big brown bats had flight capabilities that did not preclude them from using the surrounding habitat.

\section{Thermal Microclimate}

Different decay dynamics should influence temperature regimes within cavities of conifer snags and aspen trees. A study by Burnett and August (1981) on the energy budgets of a maternity colony of building-roosting little brown bats offers insight as to why the $5^{\circ} \mathrm{C}$ daytime difference between aspen and conifer snag cavities may be an important criterion in the selection of roost sites by big brown bats. At noon, unoccupied little brown roosts are $30^{\circ} \mathrm{C}$ as compared with $35^{\circ} \mathrm{C}$ for occupied roosts. The thermoneutral zone for little brown bats is between 32.5 and $37.5^{\circ} \mathrm{C}$, which puts the temperature of occupied roosts within the thermoneutral zone. However by occupying a roost, little brown bats increase the temperature by $5^{\circ} \mathrm{C}$. Hence, a roost much warmer than $30^{\circ} \mathrm{C}$ would be unsuitable for little brown bats because, once occupied, the temperature within the roost would approach or exceed the upper limit of the thermoneutral zone for bats. In a tree cavity, the effect of roost occupation by a maternity colony of big brown bats would be greater because the volume of a tree cavity is much smaller than that of an attic in a building. In addition, we found relative humidity of roost cavities to be $1.3 \%$ higher than ambient, and any effect of roost occupation on roost temperature would be enhanced by a high relative humidity inside the roost. We suggest that the difference in morning temperature between aspen and conifer snag cavities may render conifer snag cavities unsuitable as roost sites for big brown bats.

\section{MANAGEMENT IMPLICATIONS}

From a conservation perspective, roosts are the most important resource for many bat species (reviewed in Barclay and Brigham 1996). The pervasive use of human structures by big brown bats in North America (Williams and Brittingham 1997) suggests that either suitable natural sites no longer exist or that buildings are preferred roost sites. In the Okanagan Valley of British Columbia, big brown bats roosted in trees despite the presence of human structures, which supports the hypothesis that use of buildings may be the result of a loss of natural sites (Brigham 1991). Although roost sites are not limiting for building-roosting big brown bats in Ontario, individuals experimentally excluded from roosts often attempted to find alternative entrances to their original roost site and had decreased reproductive success in alternate sites (Brigham and Fenton 1986).

If we assume bats select roosts that maximize their reproductive success, then mature aspen trees with old sapsucker nest cavities are critical for the survival and fitness of the big brown bat population in Cypress Hills. Given the widespread distribution of big brown bats and aspen trees, this conclusion may have general applicability. Furthermore, because all of the randomly selected aspen cavities in our study showed evidence of use by bats, roost sites for big brown bats may be limited.

Where bats are secondary cavity users, the selection of sites used by primary cavity excavators probably influences the population numbers and community composition of bats, just as the local distributions and abundances of secondary cavity-nesting birds are enhanced by the availability of old nest cavities (Daily 1993). In western Canada, little is known about biodiversity relations of aspen mixed-wood forests because most studies have concentrated on conifer-dominated canopies (Stelfox 1995). However, it is clear that primary cavity excavators such as the yellow-bellied sapsucker prefer old, aspen-mixed-wood stands (Schieck and Nietfeld 1995). Thus, harvesting practices which promote the maintenance of large, old stands of mixed-wood forests must be implemented to provide an adequate density of aspen for treeroosting big brown bats. 
Kalcounis, M.C. and R.M. Brigham. 1998. Secondary use of aspen cavities by tree roosting big brown bats. Journal of Wildlife Management 62(2): 603-611. Made available courtesy of the Wildlife Society: http://joomla.wildlife.org/

\section{ACKNOWLEDGMENTS}

Invaluable assistance in the field was provided by D. J. Bender, D. L. Gummer, and K. R. Hecker. We appreciate use of the Department of Biology, University of Regina Field Station and acknowledge the hospitality of the West Block of Cypress Hills and Fort Walsh park administrators and employees. The suggestions of C. D. Ankney, G. A. Baldassarre, D. W. Inouye, P. M. MacDonald, R. J. O'Connor, J. E. Thompson, M. G. Topping, and M. J. Vonhof improved earlier versions of this manuscript. This research was funded by grants from the Regina Natural History Society and the Theodore Roosevelt Memorial Fund (American Museum of Natural History) to MCK and a Natural Science and Engineering Research Council of Canada (NSERC) research grant and University of Regina President's NSERC grant to RMB. MCK was supported by an NSERC postgraduate scholarship while writing this manuscript.

\section{LITERATURE CITED}

ADAMS, R. A. 1997. Onset of volancy and foraging patterns of juvenile little brown bats, Myotis lucifugus. Journal of Mammalogy 78:239-246.

$\rightarrow$ Austin, G. T. 1976. Behavioral adaptations of the verdin to the desert. Auk 93:245-262.

BARCLAY, R. M. R, AND R. M. BRIGHAM, editors. 1996. Bats and forests symposium. British Colombia Ministry of Forests, Victoria, British Columbia, Canada.

Basham, J. T. 1958. Decay of trembling aspen. Canadian Journal of Botany 36:491-505.

BRIGHAM, R. M. 1991. Flexibility in foraging and roosting behaviour by the big brown bat (Eptesicus fuscus). Canadian Journal of Zoology 69:117121.

—, AND R. M. R. BARCLAY. 1996. Bats and forests. Pages XI-XIV in R. M. R. Barclay and R. $\mathrm{M}$. Brigham, editors. Bats and forests symposium. British Colombia Ministry of Forests, Victoria, British Columbia, Canada.

- AND M. B. FENTON. 1986. The influence of roost closure on the roosting and foraging behaviour of Eptesicus fuscus (Chiroptera: Vespertilionidae). Canadian Journal of Zoology 64:11281133.

BUCHLER, E. R. 1980. Development of flight, foraging and echolocation in Myotis lucifugus. Behavioral Ecology and Sociobiology 6:211-218.

Burnett, C. D., AND P. V. August. 1981. Time and energy budgets for day roosting in a maternity colony of Myotis lucifugus. Journal of Mammalogy 62:758-766.

ChurChILl, S. K. 1991. Distribution, abundance and roost selection of the orange horseshoe-bat, Rhinonycteris aurantius, a tropical cave-dweller. Wildlife Research 18:343-353.

Crockett, A. B., and H. H. Hadow. 1975. Nest site selection by Williamson and red-naped sapsuckers. Condor 77:365-368.

DAILY, G. C. 1993. Heartwood decay and vertical distribution of red-naped sapsucker nest cavities. Wilson Bulletin 105:674-679

Entwistle, A. C., P. A. Racey, and J. R. Speakman. 1997. Roost selection by the brown long-eared bat, Plecotus auritus. Journal of Applied Ecology 34:399-408.

ERSKINE, A. J. 1960. Further notes on interspecific competition among hole-nesting ducks. Canadian Field-Naturalist 74:161-162.

- AND W. D. MCCLAREN. 1972. Sapsucker nest holes and their use by other species. Canadian Field-Naturalist 86:357-361.

Fenton, M. B., and I. L. Rautenbach. 1986. A comparison of the roosting and foraging behaviour of three species of African insectivorous bats (Rhinolophidae, Vespertilionidae, and Molossidae). Canadian Journal of Zoology 64:2860-2867.

HagGerTy, T. M. 1995. Nest-site selection, nest design and nest-entrance orientation in Bachman's sparrow. Southwestern Naturalist 40:62-67.

INOUYE, D. W. 1976. Non-random orientation of entrance holes to woodpecker nests in aspen trees. Condor 78:101-102.

INOUYE, R. S., N. J. Huntly, AND D. W. INOUYE. 1981. Non-random orientation of gila woodpecker nest entrances in saguaro cacti. Condor 83:8889

KaLCOUNIS, M. C. 1995. Natural roost site selection by big brown bats (Eptesicus fuscus). Thesis, University of Regina, Regina, Saskatchewan, Canada. , AND R. M. BRIGHAM. 1994. Impact of predation risk on emergence by little brown bats, Myotis lucifugus (Chiroptera: Verspertilionidae), from a maternity colony. Ethology 98:201-209.

- - AND R. M. BRIGHAM. 1995. Intraspecific variation in wing loading affects habitat use by little brown bats (Myotis lucifugus). Canadian Journal of Zoology 73:89-95.

KILHAM, L. 1971. Reproductive behavior of yellowbellied sapsuckers 1. Preference for nesting in Fomes-infected aspens and nest hole interrelations with flying squirrels, raccoons, and other animals. Wilson Bulletin 83:159-171.

KOROL, J. J., AND R. L. HuTTO. 1984. Factors affecting nest site location in gila woodpeckers Condor 86:73-78.

Kurta, A. 1980. The bats of southern lower Michigan. Thesis, Michigan State University, East Lansing, Michigan, USA

- J. Kath, E. L. Smith, R. Foster, M. W. ORICK, AND R. Ross. 1993a. A maternity roost of the endangered Indiana bat (Myotis sodalis) in an unshaded, hollow, sycamore tree (Platanus occidentalis). American Midland Naturalist 130 405-407.

— D. King, J. A. Teramino, J. M. Stribley, AND K. J. Williams. 1993b. Summer roosts of the endangered Indiana bat (Myotis sodalis) on the northern edge of its range. American Midland Naturalist 129:132-138.

LEwIS, S. E. 1995. Roost fidelity of bats: a review. Journal of Mammalogy 76:481-496. 1996. Low roost-site fidelity in pallid bats: 
Kalcounis, M.C. and R.M. Brigham. 1998. Secondary use of aspen cavities by tree roosting big brown bats. Journal of Wildlife Management 62(2): 603-611. Made available courtesy of the Wildlife Society: http://joomla.wildlife.org/

associated factors and effect on group stability Behavioral Ecology and Sociobiology 39:335-344 MCClelland, B. R., S. S. Frissell, W. C. Fischer, AND C. H. HALVORSON. 1979. Habitat management for hole-nesting birds in forests of western larch and Douglas-fir. Journal of Forestry 77:480 483.

$\rightarrow$ Norberg, U. M., AND J. M. V. Rayner. 1987. Ecological morphology and flight in bats (Mammalia; Chiroptera): wing adaptations, flight performance, foraging strategy and echolocation. Proceedings of the Royal Society of London Series B 316:335-427.

Peterson, E. B., AND N. M. Peterson. 1992. Ecology, management, and use of aspen and balsam poplar in the prairie provinces, Canada. Forestry Canada, Northern Forestry Centre, Edmonton, Alberta, Canada.

RELLER, A. W. 1972. Aspects of behavioral ecology of red-headed and red-bellied woodpeckers American Midland Naturalist 88:270-290.

SAUCHYN, D. J. 1993. Quaternary and late Tertiary landscape evolution in the western Cypress Hills. Pages 46-58 in D. J. Sauchyn, editor. Quaternary and late Tertiary landscapes of southwestern Saskatchewan and adjacent areas. Canadian Plains Research Centre, Regina, Saskatchewan, Canada.

SChIECK, J., AND M. NiETfELD. 1995. Bird species richness and abundance in relation to stand age and structure in aspen mixedwood forests in $\mathrm{Al}$ berta. Pages 115-157 in J. B. Stelfox, editor. Relationships between stand age, stand structure, and biodiversity in aspen mixed wood forests in Alberta. Alberta Environmental Centre, Vegreville, Edmonton, and Canadian Forest Service, Edmonton, Alberta, Canada.

Smith, D. G., A. Devine, and R. Gilbert. 1987. Screech owl roost site selection. Birding 19:6-15.
Speakman, J. R., D. J. Bullock, L. A. Eales, and P. A. RACEY. 1992. A problem defining temporal pattern in animal behaviour: clustering in the emergence behaviour of bats from maternity roosts. Animal Behaviour 43:491-500.

Stelfox, J. B. 1995. Introduction. Pages 1-12 in J. B. Stelfox, editor. Relationships between stand age, stand structure, and biodiversity in aspen mixed wood forests in Alberta. Alberta Environmental Centre, Vegreville, Edmonton, and $\mathrm{Ca}$ nadian Forest Service, Edmonton, Alberta, Canada

USMAN, K. 1988. Role of light and temperature in the roosting ecology of tropical microchiropteran bats. Proceedings of the Indian Academy of Science 97:551-59.

VONHOF, M. J., AND R. M. R. BARCLAY. 1996. Roostsite selection and roosting ecology of forestdwelling bats in southern British Columbia. Canadian Journal of Zoology 74:1797-1805.

Williams, J. B. 1993. Nest orientation of orangebreasted sunbirds in South Africa. Ostrich 64:4044.

Williams, L. M., AND M. C. BRitTingham. 1997. Selection of maternity roosts by big brown bats. Journal of Wildlife Management 61:359-368

Winternitz, B. L., AND H. CAHN. 1983. Nestholes in live and dead aspen. Pages 102-106 in J. W. Davis, G. A. Goodwin, and R. A. Ockenfels, technical coordinators. Proceedings of the snag habitat management symposium. U.S. Forest Service General Technical Report RM-99.

ZAR, J. H. 1984. Biostatistical analysis. Second edition. Prentice-Hall, Upper Saddle River, New Jersey, USA.

Received 6 August 1996

Accepted 22 September 1997.

Associate Editor: O'Connor 